\title{
Functional characterization of naturally-occurring constitutively activating/inactivating mutations in equine follicle-stimulating hormone receptor
}

\author{
Munkhzaya Byambaragchaa', Tae-Young Ahn ${ }^{1}$, Seung-Hee Choi ${ }^{1}$, \\ Myung-Hwa Kang', and Kwan-Sik Min ${ }^{1,3, *}$
}

\section{* Corresponding Author: Kwan-Sik Min Tel: +81-31-670-5421, \\ E-mail:ksmin@hknu.ac.kr}

${ }^{1}$ Animal Biotechnology, Graduate School of Future Convergence Technology, Hankyong National University, Ansung 17579, Korea

2 Department of Food Science and Nutrition, Hoseo University, Asan 31499, Korea

${ }^{3}$ School of Animal Life Convergence Science Institute of Genetic Engineering, Hankyong National University, Ansung 17579, Korea

ORCID

Munkhzaya Byambaragchaa

https://orcid.org/0000-0002-0277-1816 Tae-Young Ahn

https://orcid.org/0000-0002-7769-1546 Seung-Hee Choi

https://orcid.org/0000-0002-9550-6113 Myung-Hwa Kang

https://orcid.org/0000-0003-4309-3684 Kwan-Sik Min

https://orcid.org/0000-0002-5451-3085

Submitted May 27, 2021; Revised Jun 29, 2021; Accepted Jul 12, 2021
Objective: Follicle-stimulating hormone (FSH) is the central hormone involved in mammalian reproduction, maturation at puberty, and gamete production that mediates its function by control of follicle growth and function. The present study investigated the mutations involved in the regulation of FSH receptor (FSHR) activation.

Methods: We analyzed seven naturally-occurring mutations that were previously reported in human FSHR (hFSHR), in the context of equine FSHR (eFSHR); these include one constitutively activation variant, one allelic variant, and five inactivating variants. These mutations were introduced into wild-type eFSHR (eFSHR-wt) sequence to generate mutants that were designated as eFSHR-D566G, -A306T, -A189V, -N191I, -R572C,-A574V, and $-\mathrm{R} 633 \mathrm{H}$. Mutants were transfected into PathHunter EA-parental $\mathrm{CHO}-\mathrm{K} 1$ cells expressing $\beta$-arrestin. The biological function of mutants was analyzed by quantitating cAMP accumulation in cells incubated with increasing concentrations of FSH.

Results: Cells expressing eFSHR-D566G exhibited an 8.6-fold increase in basal cAMP response, as compared to that in eFSHR-wt. The allelic variation mutant eFSHR-A306T was not found to affect the basal cAMP response or half maximal effective concentration $\left(\mathrm{EC}_{50}\right)$ levels. On the other hand, eFSHR-D566G and eFSHR-A306T displayed a 1.5- and 1.4-fold increase in the maximal response, respectively. Signal transduction was found to be completely impaired in case of the inactivating mutants eFSHR-A189V, -R572C, and -A574V. When compared with eFSHR-wt, eFSHR-N191I displayed a 5.4-fold decrease in the $\mathrm{EC}_{50}$ levels $(3,910 \mathrm{ng} / \mathrm{mL})$ and a 2.3 -fold decrease in the maximal response. In contrast, cells expressing eFSHR-R633H displayed in a similar manner to that of the cells expressing the eFSHR-wt on signal transduction and maximal response.

Conclusion: The activating mutant eFSHR-D566G greatly enhanced the signal transduction in response to FSH, in the absence of agonist treatment. We suggest that the state of activation of the eFSHR can modulate its basal cAMP accumulation.

Keywords: Equine Follicle-stimulating Hormone Receptor; Constitutive Activation; Allelic Variant Mutation; Inactivating Mutation; cAMP Responses

\section{INTRODUCTION}

Follicle-stimulating hormone receptor (FSHR) belongs to the family of class A G-protein coupled receptors (GPCR)s, which includes luteotropin/choriogonadotropin receptor (LH/CGR) and thyroid-stimulating hormone receptor (TSHR). These receptors have a large extracellular domain for ligand binding, seven transmembrane helical domains, and a cytoplasmic tail with phosphorylation sites. FSHR plays an important role on the surface of reproductive cells, including ovarian, testes tissues by binding to follicle-stimulating 
hormone (FSH) with high affinity. The receptor then uncouples from the G-receptor and the desensitized hormonereceptor complex gets internalized into the endosomes, following which most of the complex is recycled back to the cell surface and partially degraded in the lysosomes [15]. In human FSHR (hFSHR), many studies have reported the presence of naturally-occurring constitutively activating/ inactivating mutations as well as induced mutations of residues, suggesting that the signal transduction has important effects in various aspects of receptor function [6-12].

The activating mutant of FSHR, hFSHR-D576G, was first reported in a 28 -year old hypophysectomized male. The hFSHR-D567G mutant (equivalent to D566G in equine FSHR [eFSHR]) was found to display 3-fold higher basal cAMP production compared to wild-type FSHR (FSHR-wt) [8]. Thus, this suggests that this particular site is involved in the ligand-independent constitutive activation of FSHR. Located on the third intracytoplasmic loop, this mutation site is highly conserved in all glycoprotein hormone receptors [13]. The same mutation has been detected in TSHR in patients with thyroid adenoma and pseudoprecocious puberty [14,15]. The human LHR-D578G mutant, found in patient with the syndrome of familial male-limited precocious puberty, has been shown to display approximately 15- to 25-fold higher basal cAMP production in HEK 293 cells compared to hLHR-wt [16]. Thus, this activating mutant seems to play a pivotal role in the signal transduction through the receptor; specifically by increasing the basal cAMP accumulation in the absence of agonist-treatment.

The allelic variant, A307T in hFSHR (equivalent to A306T in eFSHR) was first reported in the extracellular domain following screening of the FSHR gene in patients with hypogonadotropic ovarian dysgenesis (ODG) $[1,6]$, premature ovarian failure (POF) [17], women with hypogonadotropic hypogonadism, and in infertile men [13]. hFSHR-N680S, located in the intracellular domain, was identified in cases of ODG with a normal karyotype [6] and ovarian granulosa cell tumor [18]. Patients with ovarian juvenile granulosa cell tumors have also been found to harbor polymorphisms at the 307 and 680 amino residues [18,19]. However, there is no report whether these polymorphisms have important roles in FSH binding and signal transduction. Thus, the function of the naturally-occurring polymorphisms in the FSHRs needs to be elucidated in order to characterize the receptor and ligand.

In case of the inactivating mutation, a patient with ODG was found to harbor a transition from Ala to Val at position 189; this mutation, located in the extracellular domain of hFSHR is conserved within all glycoprotein hormone receptors and within FSHRs from different species [6,20]. Upon genotyping the A189V mutation of FSHR in 15 brothers from families with ODG, 4 were identified as wild-type homozy- gotes, 6 as heterozygotes, and 5 as homozygotes, suggesting that men do not show azoospermia or absolute infertility [21]. In addition, studies demonstrate that FSH is more important for female fertility than male fertility. This mutation was identified to be homozygous in all affected females, contributed to the disease phenotype, and impaired the signal transduction in transfected mouse Sertoli cells (MSC-1 cells). The Asn191Ile mutation, close to Ala189, was also observed in a heterozygous fertile woman showing normal ovarian function [8]. However, the cAMP response to FSH was found to be completely abolished in the in vitro signal transduction. This sequence involves a potential N-linked glycosylation site; in case of rat FSHR, this mutation (N173Q) has been shown to be important for proper folding of the hormone $[22,23]$. The sequence of five amino acids, from Aal189 to Thr193, including Asn191 residue, was found to be perfectly conserved in all glycoprotein hormone receptors, suggesting its important in the signal transduction through the receptor.

Two other inactivating mutations (Ile160Thr and Arg573Cys) were reported that in a woman with secondary amenorrhea who had very high FSH concentration in the plasma, despite normal ovarian size [24]. A previous study also identified two naturally-occurring mutations (Val514Ala and Ala575Val) in a woman with primary amenorrhea and ovarian hyperstimulation syndrome (OHSS); the study showed that a dose-dependent increase in cAMP levels upon FSH stimulation was not observed in case of the Ala575Val-expressing mutant [25]. Binding affinity and cAMP accumulation were barely detected in cells expressing the D224V mutant receptor, found in a patient with primary amenorrhea [26]. The mutation (R634H) located in the cytoplasmic tail of the receptor was first described in a case of spontaneous ovarian hyperstimulation syndrome (sOHSS). The $\mathrm{R} 634 \mathrm{H}$-expressing mutant was found to decrease cAMP production in response to FSH and markedly reduce cell surface expression [27]. Recently, several other inactivating mutations and polymorphisms have been reported: -29G $>A$ identified in the promoter region by polymerase chain reaction (PCR) screening [28], -29G>A and A189V identified by PCRrestriction fragment length polymorphism [12], Ile418Ser in a patient with primary ovarian failure [29], Asp408Tyr identified by whole exome sequencing in the second transmembrane domain of FSHR [30], and a novel homozygous mutation (R59X) in exon 2 [31]. Thus, this indicates that the intracellular loop 3 and cytoplasmic tail region of FSHR play an important function in signal transduction. We also recently reported that the basal cAMP response of eelFSHR-D540G exhibited a 23-fold increase in the absence of agonist treatment [32].

Several studies on the characterization of naturally-occurring FSHR mutations have mainly focused on hFSHR. To date, nothing is known about the signal transduction of the 
naturally-occurring mutations in case of eFSHR. The goal of the present study is to determine whether the mutations that activate or inactivate hFSHR also affect eFSHR in the same way. Thus, naturally- occurring eFSHR mutations, including one constitutively activating, one allelic variant, and five inactivating mutations were generated by site-directed mutagenesis in eFSHR-wt and analyzed by in vitro functional characterization.

\section{MATERIALS AND METHODS}

\section{Materials}

The PCR kit including Ex Taq polymerase, restriction enzymes, and high-2 ligation solution were purchased from Takara (Shiga, Japan). The gels clean up system (purification kit) and cloning vector pGEMTeasy were from Promega (Madison, WI, USA). The oligonucleotides for PCR were synthesized by Genotech (Daejon, Korea). The plasmid extraction kit used was from GeneAll Biotechnology (Seoul, Korea). Opti-MEM I, penicillin \& streptomycin, and Lglutamine were purchased from Gibco BRL (Grand Island, NY, USA). Fetal bovine serum (FBS) was from Hyclone Laboratories (Logan, UT, USA). Lipofectamine 2000 was purchased from Invitrogen Corporation (San Diego, CA, USA). Human FSH, AssayComplete medium, pCMVARMS1-PK2 expression vector, and PathHunter EA-parental
CHO-K1 cells were from DiscoverX (Fremont, CA, USA). The homogeneous time-resolved fluorescence (HTRF) cAMP assay kit was purchased from Cisbio Bioassays (Codolet, France). QIAGEN Maxi plasmid kits were purchased from Qiagen Inc. (Hilden, Germany). All other reagents used were from Sigma-Aldrich (St. Louis, MO, USA) and Wako Pure Chemicals (Osaka, Japan).

\section{Site-directed mutagenesis and vector construction} eFSHR cDNA was cloned using testicular and ovarian total RNA, as previously described [32]. eFSHR mutations were introduced into eFSHR-wt sequence using overlapping PCR mutagenesis, as previously described [32,33]. For generation of the constitutively activating mutation, Asp was substituted with Gly at residue 566 and the mutant was designated as eFSHR-D566G. NheI and SacI restriction enzyme sites were added at the 5'- and 3'-ends of eFSHR-wt sequence and the stop codon was not included in the C-terminal region of the template for cloning into pCMV-ARMS1-PK2 expression vector. The allelic variant mutant (eFSHR-A306T) and inactivating mutants (identified previously in hFSHR), were constructed by introducing the corresponding mutations at the positions 189 (A189V), 191 (N191I), 572 (R572C), 574 (A574V), and $633(\mathrm{~A} 633 \mathrm{H})$ of eFSHR-cDNA, as shown in Figure 1 . The PCR products were cloned into the pGEMTeasy cloning vector. After sequencing using automated DNA se-

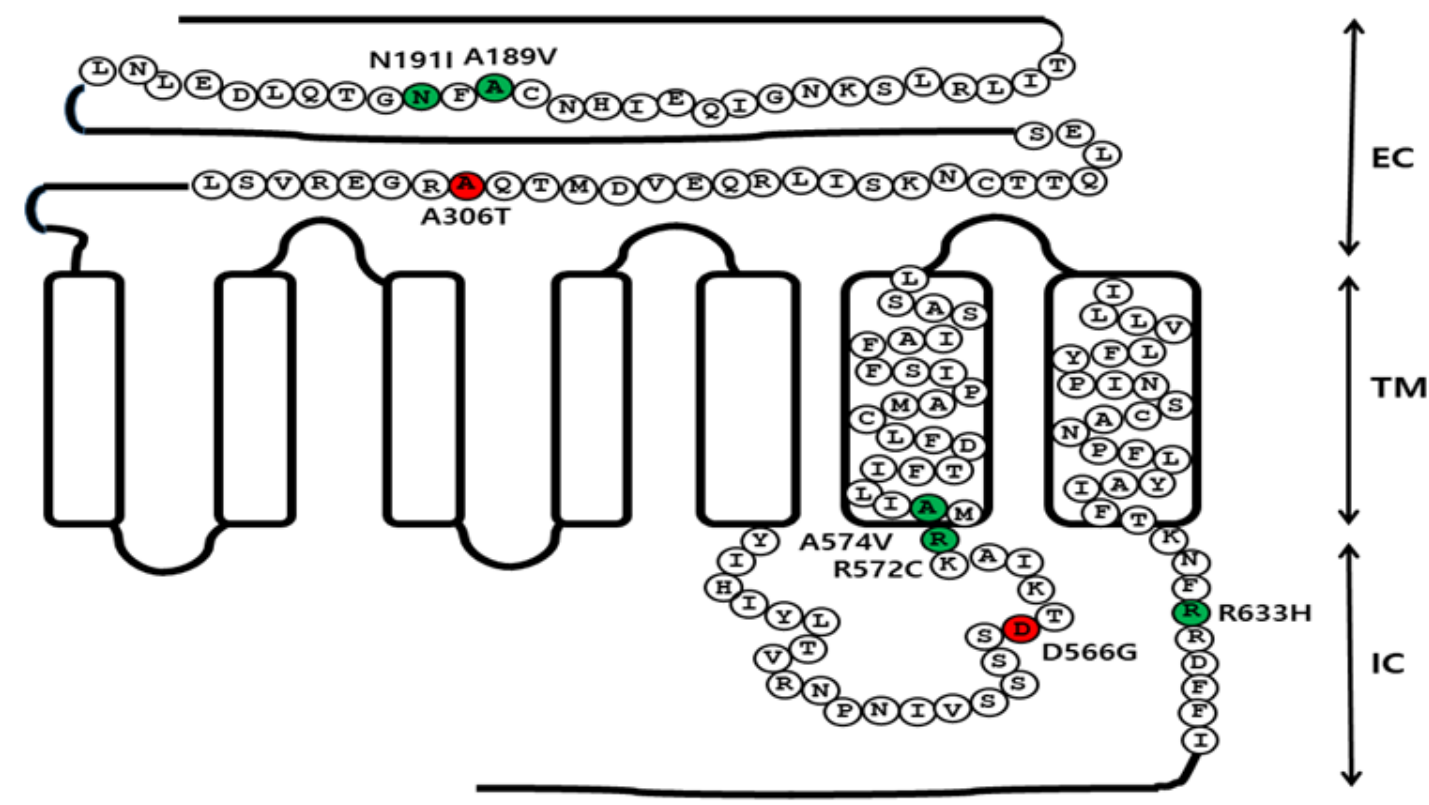

Figure 1. Schematic representation of the eFSHR structure. The location of the constitutively activating mutation (D566G), the five inactivating mutations (A189V, N191I, R572C, A574V, and R633H), and the allelic variant (A306T) are indicated in the structure of eFSHR. Red circles indicate the constitutively activating mutation and the allelic variant, while green circles indicate the inactivating mutations. Two inactivating mutations (A189V and N191I) and the allelic variant (A306T) are located in the EC domain. The activating mutation (D566G) is located in the third IC loop. The other two inactivating mutations (R572C and A574V) are located between the third IC loop region and the six TM. R633H is located in the intraplasmic tail region. eFSHR, equine follicle-stimulating hormone receptor; EC, extracellular domain; TM, transmembrane domain; IC, intracellular domain. 
quencing, the eFSHR-wt and mutant fragments were subcloned into the pCMV-ARMS1-PK2 expression vector using NheI and SacI restriction sites.

\section{Transient transfection}

PathHunter EA-parental CHO-K1 cells (engineered to stably express a fusion protein of $\beta$-arrestin and the enzyme acceptor portion of $\beta$-galactosidase) were transiently transfected with the wild-type and mutant eFSHR constructs using lipofectamine, as previously described [33]. The cells were maintained in Assay Complete $\mathrm{CHO}-\mathrm{K} 1$ culture medium supplemented with $10 \% \mathrm{FBS}, 100 \mathrm{U} / \mathrm{mL}$ penicillin, and $100 \mu \mathrm{g} / \mathrm{mL}$ streptomycin. Cells were seeded into 6-well plates $18 \mathrm{~h}$ before transfection. After the cells were washed with Opti-MEM twice, the DNA-lipid complex was added to each well gently and the plate was incubated in a humidified atmosphere with $5 \% \mathrm{CO}_{2}$ at $37^{\circ} \mathrm{C}$. Assay complete medium supplemented $(1 \mathrm{~mL})$ with $20 \%$ FBS was added to each well after $5 \mathrm{~h}$. The transfected cell medium was replaced with fresh culture medium $24 \mathrm{~h}$ post-transfection and the cells were cultured for one more day before cAMP assay was carried out.

\section{cAMP analysis by homogeneous time-resolved}

\section{fluorescence}

cAMP accumulation in PathHunter EA-parental CHO-K1 cells was measured using a cAMP Dynamic 2 competitive immunoassay kit (Cisbio Bioassays, France). Cells transfected with wild-type and mutant eFSHR-expressing constructs were suspended in a $0.5 \mathrm{mM} 3$-isobutyl-1-methylxanthine solution to prevent cAMP degradation. The cells were then seeded into 384-well white plates (Thermo Scientific, Waltham, MA, USA) at a density of $10^{4}$ cells/well, and treated with ligands (human FSH from DiscoverX, USA) in a dose-dependent manner for $30 \mathrm{~min}$ at room temperature. Following this, $5 \mu \mathrm{L}$ dye d2-labeled cAMP solution and $5 \mu \mathrm{L}$ Eu3+Cryptate-conjugated anti-cAMP antibody solution were added consistently to each assay well. After incubation for $1 \mathrm{~h}$ at room temperature, the fluorescent signal readout was carried out at $665 \mathrm{~nm}$ and $620 \mathrm{~nm}$ using a HTRF compatible Artemis K-101 microplate reader (Kyoritsu Radio, Minato-Ku, Japan). The results were calculated from the $665 \mathrm{~nm} / 620 \mathrm{~nm}$ ratio and are expressed Delta F\% (cAMP inhibition), according to the following equation:

$$
\begin{aligned}
\text { Delta F\% }= & (\text { standard or sample ratio }- \text { mock transfection }) \\
& \times 100 / \text { mock transfection }
\end{aligned}
$$

The cAMP concentrations for the Delta F\% values were calculated using Prism software (GraphPad Software, Inc, La Jolla, CA, USA).

\section{Data analysis}

The sequences were compared using Multalin interface-multiple sequence alignment tool. Each dose dependent data was analyzed from experiments performed in duplicate. The data of cAMP levels in all the transfected cells were subtracted from those in the mock-transfected cells. GraphPad Prism 6.0. was used to evaluate the differences between samples using one-way analysis of variance, followed by Turkey's multiple comparison tests. A p-value of $<0.05$ was taken to indicate a significant between the groups.

\section{RESULTS}

\section{Generation of substitution point mutants of eFSHR}

In order to identity the constitutively activating/inactivation mutations and allelic variants that contribute to the effects in respect to FSH-induced signal transduction, individual mutants were constructed by replacing each residue in eFSHRwt with the corresponding variant residues (A189V, N191I, A306T, D566G, R572C, R574V, and R633H) (Figure 1). These mutations have previously been identified as constitutively activating, inactivating, and allelic variant polymorphisms in hFSHR. Most of the selected mutations are conserved in all the glycoprotein hormone receptors, including FSHR, LHR, and TSHR. The identity of each mutant was confirmed, followed by sub-cloning into PCMV-ARMS1-PK2 and transfection into PathHunter EA-parental CHO-K1 cells expressing $\beta$-arrestin. These cells have been engineered to stably express the enzyme acceptor-tagged $\beta$-arrestin fusion protein [34]. This system can be used to detect ligand-induced activation of FSHR independent of G-protein coupling, by the co-expression of a ProLink-tagged GPCR.

\section{Signaling of constitutively activating and allelic variant mutants}

Cells transfected with eFSHR-wt DNA exhibited an increased production of cAMP in response to a high concentration of the FSH agonist. The half maximal effective concentration $\left(\mathrm{EC}_{50}\right)$ of the eFSH-stimulated cAMP response was approximately $765.1 \mathrm{ng} / \mathrm{mL}$ (Figure 2). The basal and Rmax cAMP responses were 0.9 and $20.3 \mathrm{nM} / 10^{4}$ cells, respectively. The D566G mutation induced constitutive activation of eFSHR, as demonstrated by an 8.6-fold increase in the cAMP response, which was detected in the basal condition without the presence of the agonist. The maximal cAMP response elicited by the activating mutant was approximately 1.5 -fold that of the wild-type, as shown in Table 1. cAMP production in the absence of agonist treatment indicates that the eFSHR-D566G mutant is constitutively active. Thus, cells expressing the mutation at this site show with a similar dose-dependent increase in cAMP response as the wild-type cells, but a higher basal cAMP accumulation, regardless of species, including 

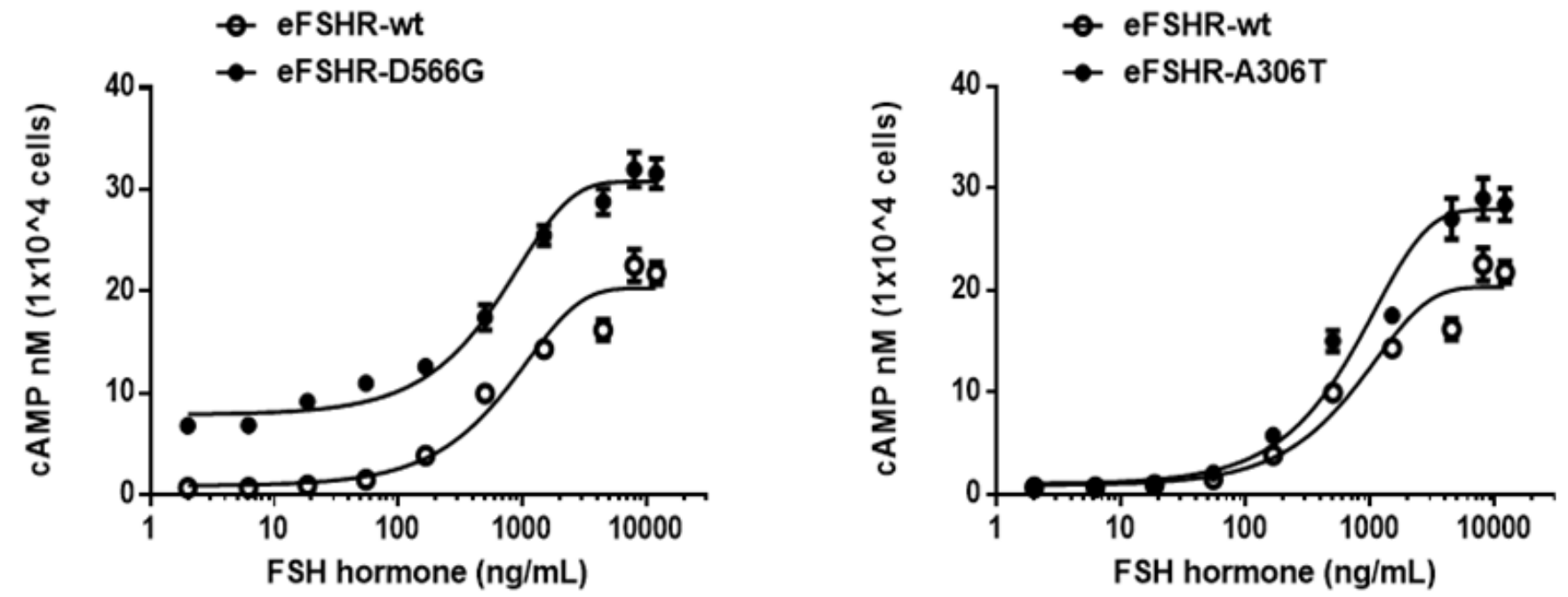

Figure 2. Total CAMP levels stimulated by FSH in PathHunter EA-parental $\mathrm{CHO}-\mathrm{K} 1$ cells transfected with constitutively active and allelic variant eFSHR mutants. PathHunter EA-parental CHO-K1 cells transiently transfected with wild-type and mutant (D566G and A306T) eFSHRs were stimulated with FSH in a medium containing $0.5 \mathrm{mM} 3$-isobutyl-1-methyl xanthine for $30 \mathrm{~min}$. cAMP production was detected using homogeneous time-resolved fluorescence assay. The cAMP accumulation is represented as Delta F\%. CAMP concentration was recalculated and presented using GraphPad Prism software. The results of the mock-transfected cells subtracted from each data set (see Methods). Each point represents the average \pm standard error of the mean of triplicate experiments. The mean data were fitted to the equation for a one-phase exponential decay curve. The blank circles were the same curves of wild-type receptor. FSH, equine follicle-stimulating hormone; eFSHR, equine follicle-stimulating hormone receptor.

fish [32].

Polymorphic variant screening identified allelic variants at two positions (A307T and N680S) in infertile men and POF patients. Of the two of them, we characterized the eFSHRA306T mutant (located in the extracellular domain) in vitro in transiently transfected PathHunter EA-parental CHO-K1 cells. As shown in Figure 2, cAMP production in response to increasing concentrations of FSH was found to be similar in the eFSHR-A306T mutant-expressing and eFSHR-wt-expressing cells. The Rmax response was 1.4 -fold higher in eFSHR-A306T-transfected cells, as compared to eFSHR-wttransfected cells (Table 1). However, the $\mathrm{EC}_{50}$ level of the eFSHR-A306T allelic mutant $(751.2 \mathrm{ng} / \mathrm{mL})$ was similar to that of the wild-type receptor $(765.1 \mathrm{ng} / \mathrm{mL})$. Thus, in terms of cAMP response induced by FSH agonist treatment, the eFSHR-A306T allelic mutant showed no difference from eFSHR-wt.

FSH-stimulated cAMP accumulation in cell lines expressing inactivating mutants

The ability of the mutant eFSHRs to transduce FSH was measured by quantitating cAMP accumulation in cells incubated with increasing concentrations of FSH (Figure 3; Table 2). As shown in Table 2, there was a profound effect on the FSH responsiveness of eFSHR-A189V, -N191I, -R572C, and $-\mathrm{A} 574 \mathrm{~V}$. The maximal response of cells transfected with these mutants was shown to be greatly reduced when compared to the equine wild-type control receptor.
Mutants harboring the eFSHR-R572C and -A574V variants were completely ineffective in cAMP accumulation, despite the high concentration of FSH. There was a 3.5- and 2.2-fold reduction in the maximal response of the other two mutants, eFSHR-A189V and -N191I, when compared to that of the wild-type control.

The $\mathrm{EC}_{50}$ of eFSHR-A189V as well as eFSHR-R572 and -A574V was not estimated, while the $\mathrm{EC}_{50}$ of eFSHR-N191I

Table 1. Bioactivity of eFSH receptors in cells expressing wild-type as well as activating and allelic mutations

\begin{tabular}{|c|c|c|c|}
\hline \multirow[b]{2}{*}{$\begin{array}{l}\text { eFSH } \\
\text { receptors }\end{array}$} & \multicolumn{3}{|c|}{ cAMP responses } \\
\hline & $\begin{array}{c}\text { Basal }^{1)} \\
\left(\mathrm{nM} / 10^{4} \text { cells) }\right.\end{array}$ & $\begin{array}{c}E_{50}{ }^{2)} \\
(\mathrm{ng} / \mathrm{mL})\end{array}$ & $\begin{array}{c}\mathrm{Rmax}^{3)} \\
\text { (nM/10 cells) }\end{array}$ \\
\hline eFSHR-wt & $\begin{array}{l}0.9 \pm 0.1 \\
(1-\text { fold })\end{array}$ & $\begin{array}{c}765.1 \\
(599.7 \text { to } 1,056)^{4)}\end{array}$ & $\begin{array}{c}20.3 \pm 2.1 \\
(1-f o l d)\end{array}$ \\
\hline eFSHR-D566G & $\begin{array}{l}7.8 \pm 0.4 \\
\text { (8.6-fold) }\end{array}$ & $\begin{array}{c}648.4 \\
\text { (543.7 to 803) }\end{array}$ & $\begin{array}{l}30.7 \pm 2.5 \\
(1.5 \text {-fold })\end{array}$ \\
\hline eFSHR-A306T & $\begin{array}{l}0.9 \pm 0.2 \\
(1 \text {-fold })\end{array}$ & $\begin{array}{c}751.2 \\
\text { (609.7 to 978.1) }\end{array}$ & $\begin{array}{l}27.9 \pm 2.4 \\
(1.4 \text {-fold })\end{array}$ \\
\hline
\end{tabular}

Values are expressed as means \pm standard error of the mean of triplicate experiments

The half maximal effective concentration $\left(E_{5}\right)$ values were determined from the concentration-response curves of the in vitro bioassays. The basal cAMP responses and Rmax in wild-type eFSHR have been represented as 1 -fold

${ }^{1)}$ Average basal cAMP levels without agonist treatment.

2) Half maximal effective concentration.

${ }^{3)}$ Rmax average cAMP level $/ 10^{4}$ cells

4) Geometric mean ( $95 \%$ confidence limit). 

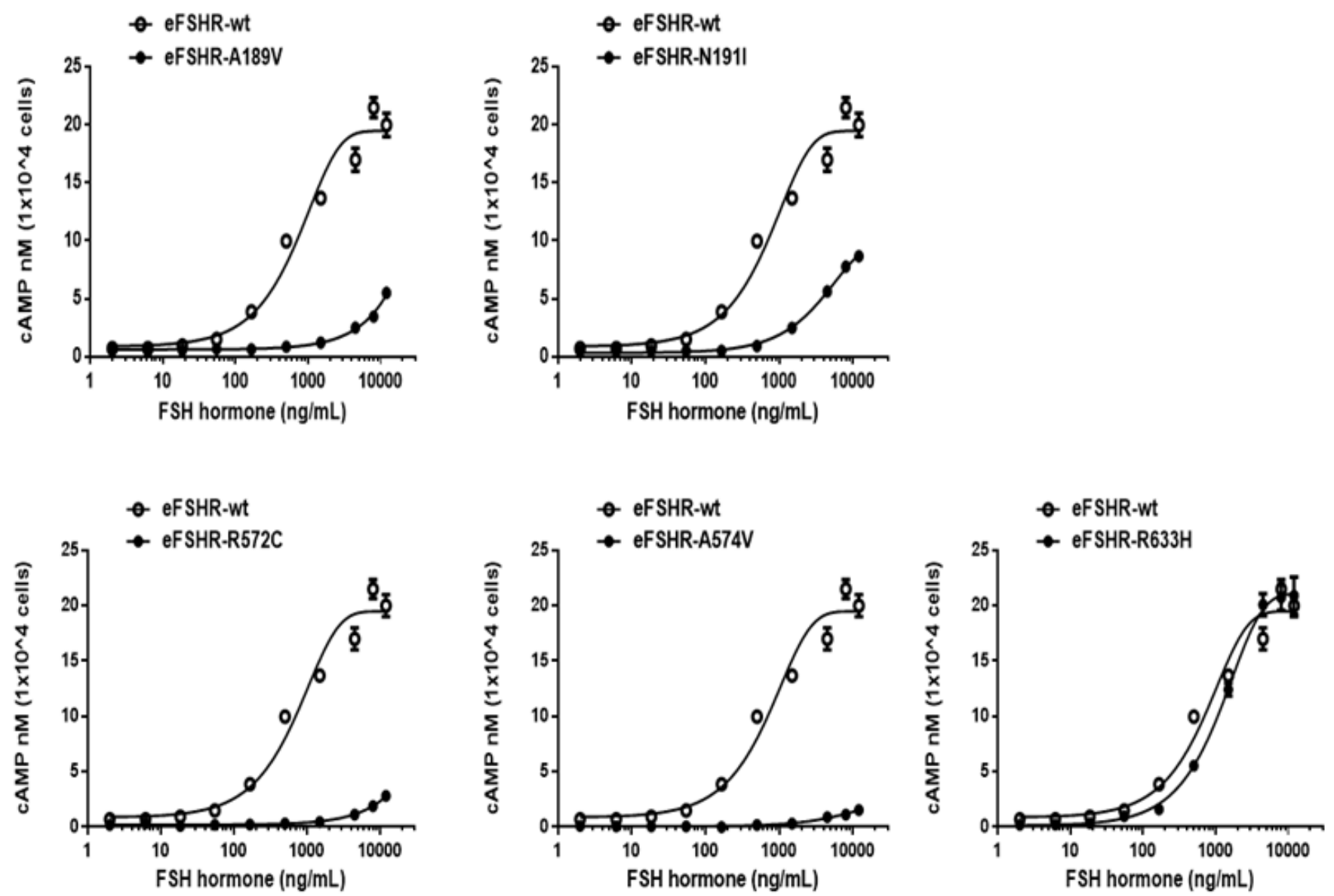

Figure 3. cAMP production, stimulated by FSH treatment, in PathHunter EA-parental CHO-K1 cells transfected with inactivating eFSHR mutants. PathHunter EA-parental CHO-K1 cells transiently transfected with wild-type eFSHR and eFSHR inactivating mutants (eFSHR-A189V, -N191I, -R572C, -A574V, and -R633H) were stimulated with FSH for 30 min. Total cAMP accumulation was analyzed using a homogeneous time-resolved fluorescence assay. The empty circles denote wild-type eFSHR and black circles denote the mutants. The values for the mock-transfected cells subtracted from each data point. Each point represents the average \pm standard error of the mean of triplicate experiments. The mean data were fitted to the equation for a one-phase exponential decay curve. FSH, equine follicle-stimulating hormone; eFSHR, equine follicle-stimulating hormone receptor.

was found to be approximately 5.4 -fold $(3,910 \mathrm{ng} / \mathrm{mL})$ lower. The mutant eFSHR-R633H, carrying the mutation in the cytoplasmic tail, showed similar $\mathrm{EC}_{50}$ and Rmax levels as the wild-type receptor, an effect identified in case of the allelic variant mutant eFSHR-A306T as well (Figure 4).

\section{DISCUSSION}

The present study analyzed allelic variants in eFSHR as well as mutations known to induce constitutively activating/inactivating signal transduction, in order to confirm if they have similar functionality as previously reported hFSHR mutations that are known to cause ODG, POF, and sOHSS. We constructed seven eFSHR mutants that are highly conserved among glycoprotein hormone receptors. These mutants either considerably stimulated basal cAMP accumulation in the absence of agonist treatment (eFSHR-D566G) or completely impaired agonist-induced activation of the receptor (eFSHRA189V, -N191I, -R572C, and -A574V). The allelic variant mutant (eFSHR-A306T) and the inactivating mutant (eFSHR$\mathrm{R} 633 \mathrm{H}$ ) showed effects that were similar to those of eFSHRwt.

In the present study, eFSHR-D566G (known as the constitutively active mutant) showed remarkably increased basal cAMP responsiveness in the absence of agonist treatment. The chimeric receptor of FSHR-LHR (FL-VC), containing the D567G mutant and the portion of the $\mathrm{LH}$ receptor from the transmembrane domain $\mathrm{V}$ to the carboxyl terminus, led to constitutive activation of the receptor, with a 7.8-fold increase in basal cAMP response as compared to wild-type FL-VC [35]. A study showed that there is impaired posttranslational processing of the $73-\mathrm{kDa}$ form of the rLHRD556G mutant receptor into the mature $92-\mathrm{kDa}$ receptor at the Golgi, which prevents its trafficking to the cell surface 
Table 2. Bioactivity of eFSH receptors in cells expressing inactivating receptor mutations

\begin{tabular}{|c|c|c|c|}
\hline \multirow{2}{*}{$\begin{array}{l}\text { eFSH } \\
\text { receptors }\end{array}$} & \multicolumn{3}{|c|}{ cAMP responses } \\
\hline & $\begin{array}{c}\text { Basal }^{1)} \\
\text { (nM/10 cells) }\end{array}$ & $\begin{array}{c}\mathrm{EC}_{50}{ }^{2)} \\
(\mathrm{ng} / \mathrm{mL})\end{array}$ & $\begin{array}{c}\mathrm{Rmax}^{3)} \\
\text { (nM/10 cells) }\end{array}$ \\
\hline eFSHR-wt & $0.8 \pm 0.2$ & $\begin{array}{c}718.0 \\
(589.7 \text { to } 917.4)^{4)}\end{array}$ & $\begin{array}{l}19.5 \pm 1.6 \\
(1-\text { fold })\end{array}$ \\
\hline eFSHR-A189V & $0.6 \pm 0.1$ & $-5)$ & $\begin{array}{c}5.6 \pm 0.3 \\
(0.3-\text { fold })\end{array}$ \\
\hline eFSHR-N191I & $0.3 \pm 0.1$ & $\begin{array}{c}3,910 \\
(3,532 \text { to } 4,378)\end{array}$ & $\begin{array}{l}8.5 \pm 0.7 \\
(0.4-\text { fold })\end{array}$ \\
\hline eFSHR-R572C & $0.3 \pm 0.1$ & - & - \\
\hline eFSHR-A574V & $0.2 \pm 0.1$ & - & - \\
\hline eFSHR-R633H & $0.3 \pm 0.1$ & $\begin{array}{c}1,160 \\
(1,053 \text { to } 1,292)\end{array}$ & $\begin{array}{l}22.2 \pm 1.7 \\
(1.1 \text {-fold })\end{array}$ \\
\hline
\end{tabular}

Values are expressed as mean \pm standard error of the mean of triplicate experiments.

EC50 values were determined from the concentration-response curves of the in vitro bioassays. Rmax cAMP response of the wild-type eFSHR has been represented as 1-fold.

1) Average basal cAMP levels without agonist treatment.

2) Half maximal effective concentration.

3) Rmax average cAMP level $/ 10^{4}$ cells.

4) $95 \%$ confidence intervals

5) Nondetectable.
[36]. Cells expressing rFSHR-3L, with a mutation of T/S to $\mathrm{A}$ in the third intracellular loop, exhibited high-basal cAMP responsiveness and an elevated maximal response to $\mathrm{FSH}$ [37]. Deletions in the intracellular loop connecting TM 5 and TM 6 of the FSHR resulted in drastically reduced membrane expression, indicating the importance of the intracellular loop for signal transduction [38]. These results are consistent with our data, showing that eFSHR-D566G is constitutively active in the absence of agonist treatment. Recently, we also reported that the eelFSHR-D540G mutant in fish produced a 23.2-fold increase in basal cAMP production [32]. Thus, we suggest that these activating sites, including eFSHR-D566G in FSHRs have the same functionality in terms of basal cAMP response. This may be a result of a change in FSHR conformation, caused by the amino acid residue transition. Recently, it was shown that transgenic mice expressing the hFSHRD567G mutant gene in the Sertoli cells, displayed increased specific binding of FSH to the testis membrane and elevated constitutive cell signaling [39]. The FSHR in transgenic mice is probably not translated into the functional receptor protein [40], suggesting that the D576G mutation confers autonomous signaling and steroidogenic activity in vivo [41]. Thus, we believe that the activating sites of the third intracellular loop in FSHR seem to be essential for FSH-FSHR interac-
A)

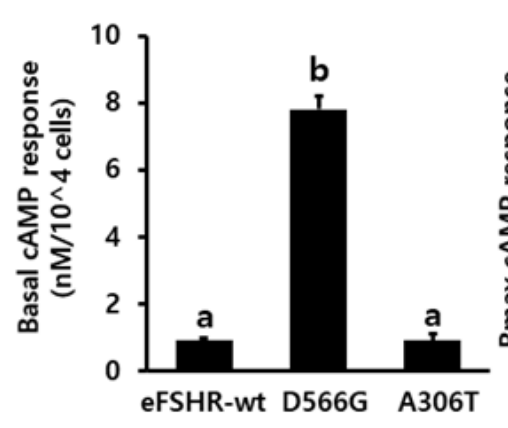

C)

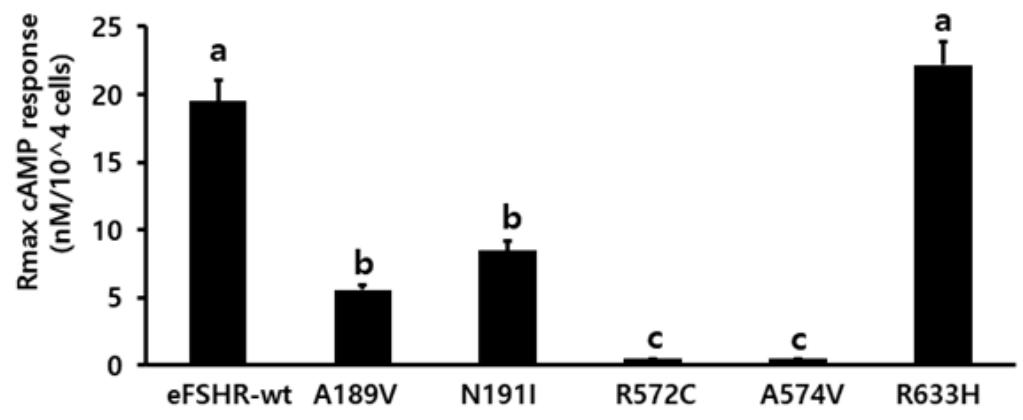

Figure 4. Determination of cAMP production in PathHunter parental $\mathrm{CHO}-\mathrm{K} 1$ cells transiently expressing the wild-type and mutant eFSHRs. CAMP production in cells expressing the wild-type and mutant eFSHRs. (A) Basal accumulation in the absence of agonist treatment; (B) Rmax levels among eFSHR-wt and eFSHR mutants with activating mutation D566G and allelic variant A306T, and (C) Rmax levels among eFSHR-wt and eFSHR inactivating mutants. Data have been expressed as mean \pm standard error of the mean of triplicate experiments. eFSHR, equine follicle-stimulating hormone receptor. Values with different superscripts were significantly different $(p<0.05)$. 
tion and FSH-induced cAMP response. Further studies will need to be carried out to understand why these activating mutants cause an elevation in basal cAMP production and are common in patients with ODG, POF, and sOHSS.

The other activating mutants were reported in the rFSHRD580G and hFSHR-D581G, suggesting that the D580G mutation in the TM 6 caused marked constitutive activation [10]. Substitution of hFSHR-L460 with K, A, or D suggested that only L460R mutant displayed constitutive activation [9]. The substitution of hFSHR-L460 and hLHR-L457 with R was reported the strongest constitutively activating mutants, suggesting that basal activity was very similar for remarkable structural similarities between hFSHR and hLHR [11]. In the present studies, we did not analyze the eFSHR-D580G and L459R mutants. Thus, further experiments are needed to explore the signal transduction for these two mutants.

Our results also demonstrated that the Rmax levels of the eFSHR-A306T mutant were 1.4-fold higher than those observed in case of the wild-type receptor, although the $\mathrm{EC}_{50}$ levels were almost similar. This polymorphism, along with the one at the 680th amino acid residue, were identified in patients with ODG, POF, and in infertile man $[6,42,43]$. Several other studies in different populations showed no such association with these diseases $[12,17,44]$. Recently, the polymorphisms A307T and S680N were reported in three out of four patients with ovarian juvenile granulosa cell tumors and in the three out of five controls [19]. hFSHR mutations do not play a pathogenic role in male idiopathic infertility, indicating similar binding affinities and cAMP responsiveness upon FSH treatment [1]. Amino acid sequence comparison results show that the position 306 is occupied by Ala in equine, bovine, ovine, and human sequences [45-47], whereas position 680 is occupied by Asn in these animals and by Ser in human. The single-strand conformation polymorphism was found to have a statistically significant difference in its genotypic distribution among the controls, POF, and diminished ovarian reserve groups; but no other variants were observed in hFSHR exon 10 [12]. Thus, our results in eFSHR-A306T are consistent with previously reported signal transduction research. This suggests that the eFSHR-A306T allelic variant has similar functionality in different mammalian species. However, it still remains to be understood why patients with this mutation suffer from infertility.

As predicted from the above results, the mutants analyzed in the present study (eFSHR-A189V, -N191I, -R572C, and -A574V) displayed impaired signal transduction, as previously reported in hFSHR $[6,8,24,28]$. It has been shown that the inactivating sites severely affect the signal transduction after FSH binding via a conformational change in FSHR that suppresses cell membrane targeting of FSHR [48]. Thus, our results are consistent with previously studies, which state that these inactivating mutations lead to a loss of FSHR function in cells expressing the mutant receptors. The conformational changes in the mutated receptor could explain why the inactivating mutants do not produce cAMP responses, despite of prolonged agonist stimulation. Specifically, the eFSHR-R633H is the only one to show an increase in cAMP response, similar to that seen in case of the wild-type receptor. However, these results are not consistent with a previous study that showed that hFSHR-R634H mutant displayed a lower response as compared to the wild-type receptor at high doses of FSH, but did not show any difference at low doses ( 1 to $5 \mathrm{mIU} / \mathrm{mL}$ ) [27]. Among the inactivating mutants, eFSHR-R633H mutant can be assumed to be normally expressed on the cell surface. Previous studies have reported that constitutively activating FSHR and LHR mutants are usually quickly desensitization by phosphorylation and internalization [49]. Therefore, inactivating mutant exception eFSHR-R633H are assumed that it does not internalization by ligand. Thus, we suggest that studies on the eFSHR-R633H mutant are essential to reveal the signal transduction in cells expressing this mutant receptor.

In conclusion, this study was shown that the eFSHRD556G, constitutively activating mutation-expressing receptor, displayed a significant increase in the basal cAMP production. The allelic variant-expressing mutant, eFSHR-A306T resulted in a higher maximal level as compared to the wildtype receptor, with no difference in the $\mathrm{EC}_{50}$ levels. Our data clearly showed that the four inactivating mutations (A191V, N191I, R572C, and A574V) completely impaired the signal transduction following FSH treatment. We suggest that eFSHRA189V and N191I mutants result in a total loss-of-signaling. eFSHR-R572C and A574V showed completely impaired signaling in maximal cAMP responses. Interestingly, the mutant expressing eFSHR-R633H mutation, which is present at the cytoplasmic tail, showed a dose-dependent increase in the cAMP response, similar to that observed in case of the wildtype receptor.

Thus, we suggest that the two mutants eFSHR-A306T and eFSHR-R633H, which show high cAMP responsiveness, need to be focused upon when studying the cell surface expression and receptor internalization following FSH treatment. These results are indeed significant for our understanding of signal transduction involving mutations of highly conserved amino acids in mammalian FSH receptors. Future studies should aim to identify the mechanism responsible for the structure-function relationship of these activating/inactivating and allelic variant mutants.

\section{CONFLICT OF INTEREST}

We certify that there is no conflict of interest with any financial organization regarding the material discussed in the manuscript. 


\section{FUNDING}

The authors received no financial support for this article.

\section{REFERENCES}

1. Simoni M, Gromoll J, Hoppner W, et al. Mutational analysis of the follicle-stimulating hormone (FSH) receptor in normal and infertile men: identification and characterization of two discrete FSH receptor isoforms. J Clin Endocrinol Metab 1999;84:751-5. https://doi.org/10.1210/jcem.84.2.5500

2. Min KS, Liu X, Fabritz J, Jaquette J, Abell AN, Ascoli M. Mutations that induce constitutive activations and mutations that impair signal transduction modulate the basal and/or agonist-stimulated internalization of the lutropin/choriogonadotropin receptor. J Biol Chem 1998;273:34911-9. https://doi.org/10.1074/jbc.273.52.34911

3. Krishnamurthy H, Kish H, Shi M, et al. Postendocytotic trafficking of the follicle-stimulating hormone (FSH)-FSH receptor complex. Mol Endocrinol 2003;17:2162-76. https:// doi.org/10.1210/me.2003-0118

4. Bhaskaran RS, Ascoli M. The post-endocytotic fate of the gonadotropin receptors is an important determinant of the desensitization of gonadotropin responses. J Mol Endocrinol 2005;34:447-57. https://doi.org/10.1677/jme.1.01745

5. Banerjee AA, Mahale SD. Role of the extracellular and intracellular loops of follicle-stimulating hormone receptor in its function. Front Endocrinol 2015;6:110. https://doi.org/10. 3389/fendo.2015.00110

6. Aittomaki K, Dieguez-Lucena JL, Pakarinen P, et al. Mutation in the follicle-stimulating hormone receptor gene causes hereditary hypergonadotropic ovarian failure. Cell 1995;82: 956-68. https://doi.org/10.1016/0092-8674(95)90275-9

7. Gromoll J, Simoni M, Nieschlag E. An activating mutation of the follicle-stimulating hormone receptor autonomously sustains spermatogenesis in a hypophysectomized man. J Clin Endocrinol Metab 1996;84:1367-70. https://doi.org/10. 1210/jcem.81.4.8636335

8. Gromoll J, Simoni M, Nordhoff V, Behre HM, De Geyter C, Nieschlag E. Functional and clinical consequences of mutations in the FSH receptor. Mol Cell Endocrinol 1996;125: 177-82. https://doi.org/10.1016/s0303-7207(96)03949-4

9. Tao YX, Abell AN, Liu X, Nakamura K, Segaloff DL. Constitutive activation of $\mathrm{G}$ protein-coupled receptors as a result of selective substitution of a conserved leucine residue in transmembrane helix III. Mol Endocrinol 2000;14:1272-82. https://doi.org/10.1210/mend.14.8.0503

10. Tao YX, Mizrachi D, Segaloff DL. Chimeras of the rat and human FSH receptors (FSHRs) identify residues that permit or suppress transmembrane 6 mutation-induced constitutive activation of the FSHR via rearrangements of hydrophobic interactions between helices 6 and 7. Mol Endocrinol 2002;
16:1881-92. https://doi.org/10.1210/me.2001-0199

11.Zhang M, Tao YX, Ryan GL, Feng X, Fanelli F, Segaloff DL. Intrinsic differences in the response of the human lutropin receptor versus the human follitropin receptor to activating mutations. J Biol Chem 2007;282:25527-39. https://doi.org/ 10.1074/jbc.M703500200

12. Ghezelayagh Z, Totonchi M, Zarei-Moradi S, et al. The impact of genetic variation and gene expression level of the folliclestimulating hormone receptor on ovarian reserve. Cell J 2018; 19:620-6. https://doi.org/10.22074/cellj.2018.4183

13.Simoni M, Gromoll J, Nieschlag E. The follicle-stimulating hormone receptor: biochemistry, molecular biology, physiology, and pathophysiology. Endocr Rev 1997;18:739-73. https://doi.org/10.1210/edrv.18.6.0320

14. Kleinau G, Krause G. Thyrotropin and homologous glycoprotein hormone receptors: structural and functional aspects of extracellular signaling mechanisms. Endocr Rev 2009;30: 133-51. https://doi.org/10.1210/er.2008-0044

15.Laue L, Chan WY, Hsueh AJ, et al. Genetic heterogeneity of constitutively activating mutations of the human luteinizing hormone receptor in familial male-limited precocious puberty. Proc Natl Acad Sci USA 1995;92:1906-10. https://doi.org/10. 1073/pnas.92.6.1906

16. Kraaij R, Post M, Kremer H, et al. A missense mutation in the second transmembrane segment of the luteinizing hormone receptor causes familial male-limited precocious puberty. J Clin Endcrinol Metab 1995;80:3168-72. https:// doi.org/ 10.1210/jcem.80.11.7593421

17. Whitney EA, Layman LC, Chan PJ, Lee A, Peak DB, McDonough PG. The follicle-stimulating hormone receptor gene is polymorphic in premature ovarian failure and normal controls. Fertil Steril 1995;64:518-24. https://doi.org/10.1016/ s0015-0282(16)57786-3

18. Fuller PJ, Verity K, Shen Y, Mamers P, Jobling T, Burger HG. No evidence of a role for mutations or polymorphisms of the follicle-stimulating hormone receptor in ovarian granulosa cell tumors. J Clin Endocrinol Metab 1998;83:274-9. https:// doi.org/10.1210/jcem.83.1.4509

19. Bas F, Pescovitz OH, Steinmetz R. No activating mutations of FSH receptor in four children with ovarian juvenile granulosa cell tumors and the association of these tumors with central precocious puberty. J Pediatr Adolesc Gynecol 2009;22:1739. https://doi.org/10.1016/j.jpag.2008.10.003

20. Aittomaki K, Herva R, Stenman UH, et al. Clinical features of primary ovarian failure caused by a point mutation in the follicle-stimulating hormone receptor gene. J Clin Endocrinol Metab 1996;81:3722-6. https://doi.org/10.1210/jcem.81.10. 8855829

21. Tapanainen JS, Aittomaki K, Min J, Vaskivuo T, Huhtaniemi IT. Men homozygous for an inactivating mutation of the follicle-stimulating hormone (FSH) receptor gene present variable suppression of spermatogenesis and fertility. Nat 
Genet 1997;15:205-6. https://doi.org/10.1038/ng0297-205

22.Liu X, Davis D, Segaloff DL. Disruption of potential sites for N-linked glycosylation does not impair hormone binding to the lutropin/choriogonadotropin receptor if Asn-173 is left intact. J Biol Chem 1993;268:1513-6. https://doi.org/10. 1016/S0021-9258(18)53881-3

23. Davis D, Liu X, Segaloff DL. Identification of the sites of $\mathrm{N}$-linked glycosylation on the follicle-stimulating hormone (FSH) receptor and assessment of their role in FSH receptor function. Mol Endocrinol 1995;9:159-70. https://doi.org/10. 1210/mend.9.2.7776966

24. Beau I, Touraine P, Meduri G, et al. A novel phenotype related to partial loss of function mutations of the follicle stimulating hormone receptor. J Clin Invest 1998;102:1352-9. https:// doi.org/10.1172/JCI3795

25.Desai SS, Achrekar SK, Sahasrabuddhe KA, et al. Functional characterization of two naturally occurring mutations (Val514Ala and Ala575Val) in follicle-stimulating hormone receptor. J Clin Endocrinol Metab 2015;100:E635-45. https:// doi.org/10.1210/jc.2014-3662

26. Touraine P, Beau I, Gougeon A, et al. New natural inactivating mutations of the follicle-stimulating hormone receptor: correlations between receptor function and phenotype. Mol Endocrinol 1999;13:1844-54. https://doi.org/10.1210/mend. 13.11.0370

27.Hugon-Rodin J, Sonigo C, Gompel A, et al. First mutation in the FSHR cytoplasmic tail identified in a non-pregnant woman with spontaneous ovarian hyperstimulation syndrome. BMC Med Genet 2017;18:44. https://doi.org/10.1186/s12881017-0407-6

28.Desai SS, Achrekar SK, Pathak BR, et al. Follicle-stimulating hormone receptor polymorphism (G-29A) is associated with altered level of receptor expression in granulosa cells. J Clin Endocrinol Metab 2011;96:2805-12. https://doi.org/10.1210/ jc.2011-1064

29. Katari S, Wood-Trageser MA, Jiang H, et al. Novel inactivating mutation of the FSH receptor in two siblings of Indian origin with premature ovarian failure. J Clin Endocrinol Metab 2015;100:2154-7. https://doi.org/10.1210/jc.2015-1401

30. Bramble MS, Goldstein EH, Lipson A, et al. A novel folliclestimulating hormone receptor mutation causing primary ovarian failure: a fertility application of whole exome sequencing. Hum Reprod 2016;31:905-14. https://doi.org/10. 1093/humrep/dew025

31.Liu H, Xu X, Han T, et al. A novel homozygous mutation in the FSHR gene is causative for primary ovarian insufficiency. Fertil Steril 2017;108:1050-5. https://doi.org/10.1016/j.fertn stert.2017.09.010

32. Byambaragchaa M, Kim JS, Park HK, et al. Constitutive activation and inactivation of mutations inducing cell surface loss of receptor and impairing of signal transduction of agoniststimulated eel follicle-stimulating hormone receptor. Int J
Mol Sci 2020;21:7075. https://doi.org/10.3390/ijms21197075

33. Byambaragchaa M, Kim DJ, Kang MH, Min KS. Site specificity of eel luteinizing hormone $\mathrm{N}$-linked oligosaccharides in signal transduction. Gen Comp Endocrinol 2018;268:50-6. https:// doi.org/10.1016/j.ygcen.2018.07.015

34. Morkrosiryski J, Mrimurer TM, Silvertsen B, Schwartz TW, Holst B. Modulation of constitutive activity and signaling bias of the ghrelin receptor by conformational constraint in the second extracellular loop. J Biol Chem 2012;287:33488502. https://doi.org/10.1074/jbc.M112.383240

35. Kudo M, Osuga Y, Kobilka BK, Hsueh AJW. Transmembrane regions $\mathrm{V}$ and $\mathrm{VI}$ of the human luteinizing hormone receptor are required for constitutive activation by a mutation in the third intracellular loop. J Biol Chem 1996;271:22470-8. https:// doi.org/10.1074/jbc.271.37.22470

36. Bradbury FA, Kawate N, Foster CM, Menon KMJ. Posttranslational processing in the Golgi plays a critical role in the trafficking of the luteinizing hormone/human chorionic gonadotropin receptor to the cell surface. J Biol Chem 1997; 272:5921-6. https://doi.org/10.1074/jbc.272.9.5921

37. Nakamura K, Krupnick JG, Benovic JL, Ascoli M. Signaling and phosphorylation-impaired mutants of the rat follitropin receptor reveal an activation- and phosphorylation-independent but arrestin-dependent pathway for internalization. J Biol Chem 1998;273:24346-54. https://doi.org/10.1074/jbc. 273.38.24346

38.Schulz A, Schoneberg T, Paschke R, Schultz G, Gudermann T. Role of the third intracellular loop for the activation of gonadotropin receptors. Mol Endocrinol 1999;13:181-90. https://doi.org/10.1210/mend.13.2.0233

39. Haywood M, Tymchenko N, Spaliviero J, et al. An activated human follicle-stimulating hormone (FSH) receptor stimulates FSH-like activity in gonadotropin-deficient transgenic mice. Mol Endocrinol 2002;16:2582-91. https://doi.org/10.1210/ me.2002-0032

40. Nordhoff V, Gromall J, Foppiani L, et al. Targeted expression of human FSH receptor Asp567Gly mutant mRNA in testis of transgenic mice: role of the human FSH receptor promoter. Asian J Androl 2003;5:267-75.

41.Allan CM, Lim P, Robson M, Spaliviero J, Handelsman DJ. Transgenic mutant D567G but not wild-type human FSH receptor overexpression provides FSH-independent and promiscuous glycoprotein hormone Sertoli cell signaling. Am J Physiol Endocrinol Metab 2009;296:E1022-8. https:// doi.org/10.1152/ajpendo.90941.2008

42.Loutradis D, Patsoula E, Minas V, et al. FSH receptor gene polymorphisms have a role for different ovarian response to stimulation in patients entering IVF/ICSI-ET programs. J Assist Reprod Genet 2006;23:177-84. https://doi.org/10.1007/ s10815-005-9015-Z

43. De Koning CH, Benjamins T, Harms P, et al. The distribution of FSH receptor isoforms is related to basal FSH levels in 
subfertile women with normal menstrual cycles. Hum Reprod 2006;21:443-6. https://doi.org/10.1093/humrep/dei317

44. Du J, Zhang W, Guo L, et al. Two FSHR variants, haplotypes and meta-analysis in Chinese women with premature ovarian failure and polycystic ovary syndrome. Mol Genet Metab 2010;100:292-5. https://doi.org/10.1016/j.ymgme.2010.03. 018

45. Yarney TA, Sairam MR, Khan H, Ravindranath N, Payne S, Seidah NG. Molecular cloning and expression of the ovine testicular follicle stimulating hormone receptor. Mol Cell Endocrinol 1993;93:219-26. https://doi.org/10.1016/03037207(93)90127-6

46. Houde A, Lambert A, Saumande J, Silversides DW, Lussier JG, Saumande J. Structure of the bovine follicle-stimulating hormone receptor complementary DNA and expression in bovine tissues. Mol Reprod Dev 1994;39:127-35. https://doi. org $/ 10.1002 / \mathrm{mrd} .1080390202$

47. Robert P, Amsellem S, Christophe S, et al. Cloning and sequencing of the equine testicular follitropin receptor. Biochem Biophys Res Commun 1994;201:201-7. https://doi.org/10. 1006/bbrc.1994.1689

48. Rannikko A, Pakainen P, Manna PR, et al. Functional characterization of the human FSH receptor with an inactivating Ala189Val mutation. Mol Hum Reprod 2002;8:311-7. https:// doi.org/10.1093/molehr/8.4.311

49. Tao YX. Inactivating mutations of $\mathrm{G}$ protein-coupled receptors and diseases: structure-function insights and therapeutic implications. Pharmacol Ther 2006;111:949-73. https://doi. org/10.1016/j.pharmthera.2006.02.008 